\title{
Gastronomi 4.0 Üzerine Kavramsal Bir Araștırma
}

Emrah KESKİN, Nevres SEZEN

\section{GASTRONOMİ 4.0 ÜZERINE KAVRAMSAL BİR ARAŞTIRMA}

\author{
A Conceptual Study on Gastronomy 4.0
}

\author{
* Emrah KESKIN \\ ** Nevres SEZEN
}

\section{GAS}

Yayın Bilgileri

Kabul tarihi:27.04.2021

Yayın tarihi: 16.08.2021

\author{
İletişim Bilgileri \\ * ekeskin@nevsehir.edu.tr \\ ***Nevressezen67@gmail.com
}

\begin{abstract}
ÖZET
Endüstri 4.0, dördüncü sanayi devrimidir. Turizm 4.0, ise akıllı turizmdir. Gastronomi 4.0, yiyecek-içecek sektöründe görülen yenilikçi teknolojik gelişmeler olarak ifade edilmektedir. 4.0'ın geliştirilmesi ve hayata geçirilmesi günümüz teknoloji çağındaki ilerlemelere öncü olmuştur. Teknoloji çağında endüstri alanında yaşanan gelişmeler birçok sektörün gelişimi üzerinde etkili olmaktadır. Turizm ve turizm faaliyetlerinin önemli bir bölümünü kapsayan gastronomi de, yenilikçi teknolojik gelişmelerden etkilenmektedir. Yapılan çalışmanın amacı, gastronomide 4.0'ın kullanımını araştırmak ve araştırma doğrultusunda yiyecek-içecek sektöründe yenilikçi teknoloji ürünlerinin kullanımına dair tavsiyelerde bulunmaktır. Çalışmanın amacı doğrultusunda nitel araştırma yöntemlerinden doküman incelemesi yapılmıştır. Araştırma sonucunda turizm endüstrisinde otellerde ve yiyecek-içecek işletmelerinde yenilikçi teknoloji ürünlerinden çeşitli tasarımlarda robotik cihazların kullandığına, 4.0'ın yiyecek-içecek işletmelerinde küresel anlamda bir etkide bulunduğuna, fakat robotik cihazların kullanımında tereddütlerin olduğuna dolayısıyla yenilikçi teknolojileri benimsemeyen işletmelerin de olduğuna ulaşı1mıştır.
\end{abstract}

Anahtar Kelimeler: Endüstri 4.0; Turizm 4.0; Gastronomi 4.0; Teknoloji.

\begin{abstract}
Industry 4.0 is the fourth industrial revolution while tourism 4.0 is called smart tourism. On the other hand, gastronomy 4.0 can be referred to as the technological developments experienced in food and beverage industry. The improvement of 4.0 and its applcation to life has led to the developments in today's era of technology. The improvements occuring in the realm of industry in the era of technology have been affecting the developments in a great number of sectors as well. Gastronomy, coprising of a substantial part of tourism and tourism actvities, is affected by the innovative developments, too. The aim of the research is to investigate the application of 4.0 in the realm of gastronomy and to make suggestions related to the application of technoloogical items in the sector of food and bevarages. In line with the aim of the study, an elaborate review of literature was conducted through qualitative research method. The findings that innovative robotic devices of various designs have been started to be made use of in hotels and food and baverage companies in the realm of tourism, that 4.0 has had a substantial impact on food and baverage companies globally, but that there have been hesitations regarding the use of robotic devices, thus there have been companies that have not cherished the innovative technologies.
\end{abstract}

Keywords: Industry 4.0, Tourism 4.0, Gastronomy 4.0, Technologhy 


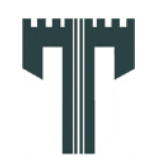

Gastroia: Journal of Gastronomy and Travel Research, Vol. 5, Issue 2,177-198 , 2021

Gastronomi 4.0 Üzerine Kavramsal Bir Araştırma

Emrah KESKIN, Nevres SEZEN

\section{GíRiş}

Teknolojide meydana gelen gelişmeler, endüstri alanında birçok yeniliğin hayata geçirilmesinde öncü olmaktadır. Başlangıç noktası Almanya' daki akıllı fabrikalara dayanan Endüstri 4.0 kavramı, dördüncü sanayi devrimini ifade etmektedir. Endüstri 4.0 ile endüstri alanında yaşanan gelişmeler, çağın teknoloji kullanımını ileri bir boyuta taşımıştır (Karakuş, 2020). Teknolojinin geldiği bu boyut üretim sonucu elde edilen ürünlerin dijital ortama yansitılmasına ve sonrasında tüm kontrolün dijital unsurlarla devam ettirilmesine katkı sağlamaktadır. Bu nedenle Endüstri 4.0 devrimi, endüstrinin bir çok alanında özellikle de turizm endüstrisinde teknolojik çağa ayak uydurması ve endüstri alanında sürdürülebilirliğin sağlanması gibi noktalarda yarar sağlamaktadır (Perakovic, Periša ve Zorić, 2019).

Endüstri 4.0'1n sunduğu teknolojik hizmetlerin, insanların kişisel bilgilerine erişim açısından özel hayatın gizliliğini tehlikeye attığına yönelik endişeler bulunmaktadır. Ancak Endüstri 4.0'1n tüm sektörlerde güvenilir biçimde kullanılması için birtakım çalışmalar yapılmıştır. Endüstri 4.0 tabanlı uygulamalara erişimde akıllı sözleşmeler, tekonizasyon, veri güvenliği, merkezi olmayan depolama, değişmezlik, mutabakat, yazılı blok, içeriklerin alt kümelere ayrılması, erişim hakları yönetimi, blok zinciri izinlerine standartlar koyulması, standart veri formatlama, güncellenebilirlik, blok zincirleri arası şifreleme yapabilme, UX (user experience) ve geliştirme operasyonları uygulamaların daha güvenilir, ulaşılabilir ve sorunsuz bir şekilde kullanılabilmesini sağlamaktadır (Bodkhe vd., 2020).

Endüstri 4.0 ile turizm başta olmak üzere endüstrinin her alanında, endüstri kapsamında elde edilen somut faktörler ve dijital ortamda işlenebilecek sanal faktörler bir araya getirilmiştir. $\mathrm{Bu}$ birleştirme verilerin iletilmesinde, yani teknolojinin endüstriyel iletişimde kullanılmasında yarar sağlamaktadır (Perakovic, Periša ve Cvitić, 2018). Ayrıca Endüstri 4.0'ın sunduğu teknolojik imkânlar, hizmete yönelik talebi arttırmada, dijital ortamdaki verimliliği arttırmada, kalite faktörlerini geliştirmede ve işletim maliyetini azaltmada da önemli rol oynamaktadır (Perakovic, Periša ve Cvitić, 2019).

Turizmde, turistik deneyim sağlayan ürünlerden beklenen teknolojik gelişmeler, Endüstri 4.0'ın Turizm 4.0 olarak kullanılmasını zorunlu kılmıştır. Destinasyonlar, Endüstri 4.0’1 turistik ürünlerde iyileştirmeye giderek, turizm potansiyelini arttırmak için kullandığından, Endüstri 4.0 turizm içerisinde olumlu yönleri ile değerlendirilerek kullanılır hâle getirilmiştir. Destinasyon yönetimine katkı sağlayan teknolojik sistemler, cep telefonlarına indirilen uygulamalar, web siteleri, eğlence sistemleri, sesli asistanlar, hizmet robotları, sanal turlar ve sanal konserler turistik hizmetlerin iyileştirilmesine katkı sağlayan Turizm 4.0 teknoloji ürünleri ile gerçekleştirilmektedir (Lehaney vd., 1999; Slivar, Stankov ve Pavluković, 2019; Cohen ve Hopkins, 2019; Murphy, Gretzel ve Pesonen, 2019; Stankov ve Gretzel, 2020; Chandler, 2020). 


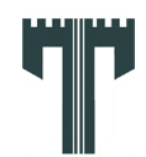

Gastroia: Journal of Gastronomy and Travel Research, Vol. 5, Issue 2,177-198 , 2021

Gastronomi 4.0 Üzerine Kavramsal Bir Araştırma

Emrah KESKIN, Nevres SEZEN

Endüstri 4.0'ın turizmde kullanılması ile turistik deneyimler için daha sorumlu ve daha donanımlı teknolojik cihazların kullanımıyla turistlere yönelik faydalı bir hizmet sunumu benimsenmiştir (Stankov ve Filimonau, 2019a). Kullanılan bu teknolojik sistemler, turistlerin turistik deneyime yönelik tutumlarında ve bir sonraki seyahat niyetlerinde etkili olmaktadır. Dolayısıyla bu sistemler, turistleri hedonik yönden etkileyebilmekte ve memnuniyetleri üzerinde etkili olmaktadır (Gretzel vd., 2015).

Turizm 4.0 etkileşimli sistem kullanımı sağlamaktadır. Turizmde etkileşimli sistem kullanımı, turistlerin turistik deneyime fiziksel, duyusal ve duygusal olarak her açıdan katılımını ifade etmektedir. İnsan merkezli olan etkileşimli sistemler sayesinde turistlerde deneyim yaşama eğilimi artmakta ve deneyimin turist üzerindeki etkilerinin uzun süreli devam etmesi sağlanmaktadır. Turizm 4.0, sağlamış olduğu birçok yenilik ve iyileştirme, destinasyonla sınırlı olan deneyimlerin daha ileri boyuta ulaştırılmasına etki etmektedir. Bundan dolayı turistler için destinasyon ötesi iyileştirme ve geliştirme firsatı sunan Turizm 4.0, turistik memnuniyetin sağlanmasına katkı sağlamaktadır. (Lessiter vd., 2018; Stankov ve Gretzel, 2020).

4.0 faaliyetleri endüstri ve turizm alanında gelişme göstermekle birlikte, yiyecek-içecek faaliyetlerinde ve gıda sektöründe de gelişmeye başlamıştır. Günümüzde yaşanan teknolojik gelişmeleri takip eden yiyecek-içecek işletmeleri, müşterilerine işletmenin teması veya atmosferi hakkında vermek istedikleri mesajı teknolojik yeniliklerin içerisinde vermektedir. Arttırılmış gerçeklik ve sanal zekâ gibi uygulamalar bu duruma örnek verilebilir. Ayrıca yemek hazırlığı yapabilen robotların üretilmesi, robotların gelecekte şeflerin yanında yer alabileceğini göstermektedir. Bundan dolayı 4.0 gelişmeleri ile üretilen robotların ve müşterileri etkileyen diğer uygulamaların gelecekte yiyecek-içecek sektöründe etkin rol oynayacağı düşünülmektedir (Linden, McClements ve Ubbink 2008; Özgüneş, Bozok ve Küçükaltan, 2020).

\section{KAVRAMSAL ÇERÇEVE}

\subsection{Turizm 4.0}

Endüstri 4.0 kavramı dünyada ilk olarak 2011 yılında Alman hükümeti tarafindan dile getirilmiştir. $\mathrm{Bu}$ kavram ilk başlarda toplumların endüstri alanında yüksek teknoloji sistemleri aracılığıyla akıllı fabrikaların meydana getirilmesine yönelik olmuştur. İlerleyen süreçte endüstri ürünlerine bilgi ve iletişim kanallarının eklenmesiyle endüstri ürünleri akıllı hale getirilmiştir. Endüstri ürünlerinin akıllı hale gelmesi firmaların uluslararası alanda sahip oldukları pazar paylarının artmasına ve ekonomik anlamda gelişmesine katkı sağlamıştır (Rodič, 2017; Diez-Olivan vd., 2019; Korže, 2019). 


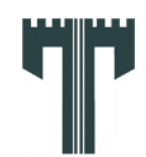

Gastroia: Journal of Gastronomy and Travel Research, Vol. 5, Issue 2,177-198 , 2021

Gastronomi 4.0 Üzerine Kavramsal Bir Araştırma

Emrah KESKIN, Nevres SEZEN

Yoğun bilgi ve geliştirilmiş teknolojiye dayanan Endüstri 4.0 uygulamaları, teknolojik ürünler sayesinde işletmelerin mevcut iş gücü yükünde azaltmaya gitmeyi hedeflemektedir (Mutlu Öztürk, 2020). Park'a (2017) göre Endüstri 4.0 kavramı, üretkenliği arttırmak ve endüstriyel üretimi yoğunlaştırmak için fiziksel ve siber sistemler arasındaki boşluğu aşabilen yapay zeka (AI), büyük veri ve robotiklere dayalı hiper otomasyon ve hiper bağlantıdır (Korže, 2019). Bu nedenle Endüstri 4.0 birçok sektörde dijitalleşme ve akı1lı çalışma ortamlarına öncü olmakta ve işletmelerin hem tasarruflu hem de verimli çalışmasına katkı sağlamaktadır (Mutlu Öztürk, 2020). Porter ve Heppelmann (2014)'a göre ise 4.0 uygulamaları dijital dönüşümün bileşenlerinden birisidir. Dolayısıyla fiziksel, dijital ve biyolojik dünyanın birleşmesini sağlayarak insan hayatında yer almaktadır (Schwab, 2016). Robotların kullanımının artması, nesnelerin interneti, yapay zekâ, sensörler, bilişsel teknolojiler, nanoteknoloji, internet hizmetleri, kuantum bilişimi, teknolojik giysiler ve takılar, arttırılmış gerçeklik, akıllı işaretleme, akıllı robotlar, büyük veri, 3D yazıcılar, yeni nesil teknolojiler ve akıllı ağlar Endüstri 4.0 kavramının oluşmasını sağlayan unsurlardır (Mutlu Öztürk, 2020).

Turizm 4.0 ise, kişiselleştirilmiş seyahat deneyimi oluşturmak için çok sayıda gezginden elde edilen mevcut büyük verileri işleme eğilimidir (Korže, 2019). Turizmde dijital dönüşüm, akıllı otomasyon, bulut bilişim, mobil internet, robotik, yapay zekâ otonom araçlar ve 3D baskı gibi teknolojik tasarımlar Turizm 4.0 kavramı oluşturan gelişmelerdir. $\mathrm{Bu}$ gelişmeler küresel alanda turizm iş gücünü arttırmaktadır (Papathanassis, 2017). Verevka'ya (2018) göre Turizm 4.0, “akıllı turizm”dir. Pencarelli’ ye (2019) göre ise, geliştirilmiş teknolojik ürünlere, sanal ortama ve bu ortamda gerçekleştirilen teknolojik çalışma yöntemlerine bağlı olarak hizmetlerin sanal yöntemlerle analiz ve kontrol edilebildiği bir platformdur. Dolayısıyla turizm endüstrisinde mal ve hizmetlerin otomatik olarak geliştirilmiş yöntemlerle yönetilmesini kapsamaktadır (Ivanov, 2020). Peraković ve arkadaşlarına (2019) göre işletmeler Endüstri 4.0'ın sağladığı akıllı teknolojik sistemler sayesinde iş ortamında verimliliğin ve iş performansının artmasına olanak sağlamaktadır. Turistlerin yanlarında taşıdıkları iletişim cihazları ve bu cihazlarda gördükleri veriler zihinsel olarak algılarını etkilemekte ve onları fiziksel ve zihinsel olarak turizmde herhangi bir yere taşıyabilmektedir. Dolayısıyla 4.0 uygulamalarının iletişim cihazlarında kullanılması, turistik aktivitelerde ve turistik hareketliliklerde değişiklik meydana gelmesinde etkilidir. Bu nedenle, 4.0 uygulamaları turistleri ve turizm işlemelerini etkileme gücüne sahip olmakla birlikte, turizmin sürdürülebilmesi için işletmeler tarafından değerli görülmektedir (Stankov ve Gretzel, 2020).

Dolayısıyla 4.0 uygulamalarının iletişim cihazlarında kullanılması, turistik aktivitelerde ve turistik hareketlenmelerde değişikler meydana gelmesinde etkilidir. Bu nedenle, 4.0 uygulamaları turistleri ve turizm işlemelerini etkileme gücüne sahip olmakla birlikte, bu 


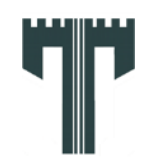

Gastroia: Journal of Gastronomy and Travel Research, Vol. 5, Issue 2,177-198 , 2021

Gastronomi 4.0 Üzerine Kavramsal Bir Araştırma

Emrah KESKIN, Nevres SEZEN

cihazların turizm işletmelerine sağladığı çevrim içi faydalardan dolayı, turizmin sürdürülebilmesi için işletmeler tarafından değerli görülmektedir.

Pecency ve arkadaşlarına (2019) göre Turizm 4.0, turizmde fiziksel ve dijital dünyayı bir araya getirerek inovasyon hareketlerini hızlandırmaktadır. Gerçekleştirilen ve gerçekleştirilecek olan inovasyonlardan yalnızca turistik tatil satın alan turistler değil, aynı zamanda destinasyon bölgesindeki yerel halk da etkilenebilmektedir. Bundan dolay turizmde Turizm 4.0 uygulamalarının pazarlanması hem turist grupları hem de yerel halk açısından fayda sağlayabilmektedir. Turizm 4.0'ın sağladığı akıllı sistemler, insanlar ile teknoloji arasındaki etkileşimi arttırmaktadır. 4.0 uygulamalarının turizm endüstrisinde kullanılması turist grupları için güven sağlayıcı olmaktadır. Bundan dolayı, Turizm 4.0 turistik deneyim kalitesi açısından önemli görülmektedir (Case, 2015).

Turizmin akıllı sistemlere odaklanması, bazı turistlerin bu teknolojik ürünlere bağlılık duymasında etkili olmuştur. Ancak, bu teknolojik ürünlerin sunduğu deneyimlerin herkese açık olma ihtimali, turistlerin deneyim aşamasındaki birtakım kişisel bilgilerinin herkes tarafından öğrenilebilir olması durumu, turistik deneyimin güvenilirliğine olan olumlu algıyı yıkabileceği düşüncesiyle eleştirilere de maruz kalmaktadır (Kim ve Qu, 2014; Dinçer, Bayram ve Altınöz, 2020; Stankov ve Gretzel, 2020).

Turizmde 4.0 gelişmeleri sonucu elde edilen teknolojik turizm araçları, turistlerin yeteneklerine ve hobilerine ulaşarak, onların beğenilerine yönelik deneyimler yaşayabilmesine olanak sağlamaktadır. Turistlerin istek, beklenti ve beğenilerini tespit edebilen teknolojik ürünler, turistlerin takdirini kazanmak için çeşitli plan ve programlara tabi tutulmaktadır. Bu nedenle turizmde teknolojik ürünlerin yönetimi, turist memnuniyeti için önem taşımaktadır (Bec vd., 2019).

Sanal gerçeklik (VR) ve arttırılmış gerçeklik (AR) Turizm 4.0 teknolojileri arasında yer alan ve turistlerin ilgisini çeken uygulamalardır. Sanal gerçeklik (VR), turistlerin gerçek veya kurgusal yerlere sanal yolculuk yapmasını sağlarken, artırılmış gerçeklik (AR) var olan, yani gerçek bir nesnenin görüntüsünün dijital yöntemlerle zenginleştirilerek izleyiciye aktarılmasını sağlamaktadır (Fes, 2018; Augment, 2016).

Avcı'ya (2020) göre artırılmış gerçekliğin oteller ve turistler açısından şu yönde avantajları bulunmaktadır;

- Otel odalarını ve oda düzenini uzaktan belirleyebilme,

- Otel veya restoran menülerinde yer alan yemeklerin belirli kodlar aracılığıyla tabaktaki son halini görme,

- Ak1llı masalar ile sipariş verme,

- Sipariş sürecini izleme, 


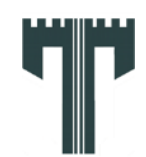

Gastroia: Journal of Gastronomy and Travel Research, Vol. 5, Issue 2,177-198 , 2021

Gastronomi 4.0 Üzerine Kavramsal Bir Araştırma

Emrah KESKIN, Nevres SEZEN

- Ören yerlerini üç boyutlu olarak izleme,

- Sanal turlara katilma,

- Müzelerde doğal hayatın akışına uygun hayvan seslerini, hayvanın canlı sesi gibi dinleyebilme (Sakıp Sabancı Müzesi, Topkapı Sarayı, Anadolu Medeniyetler Müzesi vb.) imkânı gibi müşterilerin dikkatini çekecek birçok uygulama artırılmış gerçeklik ile müşterilere sunulmakta ve çekicilik sağlanmaktadır.

Meydana gelen bu gelişmelerin yanı sıra, yakın zamanda dijital defterler üretilebilecek, bu defterlerde yolcuların kimlik ve kişisel bilgileri yer alacak ve insanlar yalnızca dijital defterlerini yanlarında taşıyarak seyahatler yapma imkânına sahip olabileceklerdir. Seyahatlerde robot ve avatar robot kullanımı ile engelli bireylerin seyahat etmelerinde yaşadığı zorlukları azaltılabilecek, aynı zamanda robotların yabancı dil bilgisine sahip olması turistler ve turistleri ağırlayan hizmet yetkilileri arasındaki iletişimin kolaylaşmasına katkı sağlayacaktır (Hausold, 2017; Cheung, Tsang ve Wong, 2017).

\subsection{Gastronomide 4.0 Kullanımı}

Yemek tüketimi, günümüzde beslenme ihtiyacının dışında da farklı anlamlar ifade etmektedir. İnsanlar yemeği beslenme ihtiyacının yanı sıra eğlenme, yeni ve çeşitli lezzetler keşfetme veya kendini gerçekleştirme amacıyla tüketebilmektedir. Yiyecek-içecek sektöründe çeşitli isteklere yönelik hazırlanan ürünlerin takibinde, geliştirilmesinde, pratik yöntemlerle hazırlanmasında, ürün satışlarının takibinde ve müşteri memnuniyetinin sürekliliğinin korunmasında birtakım teknolojik ürünlerin kullanımına ihtiyaç duyulmaktadır. Değișen ve gelişen dünyanın birçok yerinde kullanılan teknolojik ürünler, insanların beklentilerinin değişmesinde etkili olmuştur. Bundan dolayı yiyeceklerin, insanların çeşitli istek ve ihtiyaçlarına göre hazırlanması ve sunulması aşamasında Endüstri 4.0 ile elde edilen birçok teknolojik üründen yararlanılmaktadır (Şahin ve Doğdubay, 2017; Güneş vd., 2018).

Endüstri 4.0'1n akıllı gelişmelerinden yararlanan turizm endüstrisi, turizmde yaşanan deneyimlerin kalitesini yükseltmek amacıyla akıllı teknoloji ürünlerini kullanmaktadır (Neuhofer, Buhalis ve Ladkin, 2014). Ivanov, Webster ve Berezina'nın (2017) çalışmasına göre, yakın gelecekte turizm endüstrisinde yer alan servis, mutfak, restoran, eğlence vb. insan iş gücü gerektiren alanlarda yapay zekâlı robotlar iş göreceklerdir. Mil ve Dirican (2018), çalışmalarında insanların duyularının ve hislerinin elektronik ortamda karşı tarafa aktarılmasını sağlayan çalışmalar yapıldığını, bu çalışmalar sayesinde gastronomi ve restoran sektörünün arttırılmış gerçeklik uygulamalarından yararlanacağını ve bu sayede sunulan hizmetin boyutunda değişiklikler görüleceğini, değişikliklerin ise işletmelerin maliyet ve satışlarında değişiklikler meydana getirebileceğini belirtmiştir. 


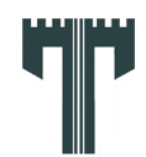

Gastroia: Journal of Gastronomy and Travel Research, Vol. 5, Issue 2,177-198 , 2021

Gastronomi 4.0 Üzerine Kavramsal Bir Araştırma

Emrah KESKIN, Nevres SEZEN

Turizm 4.0'ın meydana getirdiği teknolojik gelişmelerden gastronomi ve yiyecek-içecek işletmeleri de payını almıştır. Mobil cihazların etkin kullanımı seyahat edilen yerlere dair bilgilerin, bu yerlere ait yerel yiyecekler ile ilgili yorumların çevrim içi ortamlarda aktif olarak paylaşılması ve uzaktan rezervasyon imkânının olması, teknolojinin yiyecek-içecek sektöründeki varlığının ve etkisinin somut örneklerindendir (Aydın, 2016; Eröz ve Doğdubay, 2012).

Önemli alternatif turizm türlerinden birisi olan gastronomi turizmi, kültürün gelecek nesillere aktarılmasında önemli bir yere sahiptir. Yiyeceklerin gelecek nesillere aktarılmasında kültürel özelliklerin korunması önemlidir önemlidir (Karakuş, Onat ve Özdemir, 2020). Fakat bazı mekânlarda yiyeceklerin çağa uygun şekilde teknolojik yöntemlerin etkisiyle sunulduğu görülmektedir. Bazı restoran işletmecileri zarar ve kârı göz önünde bulundurarak restoranlarda teknolojik yeniliklerden yararlanmayı tercih etmektedir (Hall ve Sharples, 2003; Kimes, 2008). Dijital teknoloji sayesinde yemek masalarında yer alan yemek ile alakalı animasyonlar, masa ve duvarlarda bulunan ses ve 1şılklar, lezzeti arttırılmış yiyecekler, daha zevkli ve çekici hale getirilen yemek deneyimi, e-menü, içeriğinde farklı tatlar barındıran yenilebilir kâğıt, yenilebilir menü ve 3D yazıcılar aracılığıyla istenilen şekilde yiyecek yapılmaktadır. Bazı işletmelerde de yiyeceklerin menüleri, dokunmatik ekranlı cihazlarla görülebilmekte, böylelikle yemeklerin yapılış ve içeriği takip edilebilmektedir. Tüm bu gelişmelerin müşteri memnuniyetinde etkili olması, teknolojinin gastronomi ve gastronomi turizmine olan katkısını göstermektedir (Spence ve Piqueras-Fiszman, 2013; García-Segovia vd., 2014; Aksoy ve Akbulut, 2016; Ivanov vd., 2017; Mutlu Öztürk, 2020).

Yu (2020), çalışmasında animasyon gösterisi sergileyen robotlara karşı olumlu bir alg1 olduğunu fakat insansı robotların kullanımı düşünüldüğünde insanların olumsuz bir algıya kapıldıklarını açıklamıştır. Ancak Jang ve Lee'nin (2020) çalışmasında müşterilerin servis robotlarına karşı olumlu bir yaklaşım gösterdiği sonucuna ulaşmışlardır.

Restoranlarda robot kullanımı, müşteri tercihlerini ve hangi yiyeceklerin ne sıklıkla tercih edildiğini belirlemede etkili olmaktadır. $\mathrm{Bu}$ nedenle robotlar, restoranların iş planlaması yapmasına, verimlilik ve kalitenin artmasına katkı sağlamaktadır (Zhang vd., 2020). Örneğin Londra'da Inamo Restoranında kullanılan akıllı masalar, arttırılmış gerçeklik aracılığıyla müşterilere e-menüler sunmaktadır. Bu masalar müşterilerin yiyeceklerin yapım aşamasında mutfağı izlemesine ve farklı bir eğlence deneyimi yaşamalarına olanak sağlamaktadır (Aksoy ve Akbulut, 2016).

Seyitoğlu ve Ivanov (2020), çalışmalarında Covid-19'un turizme etkilerini araştırmış ve robotların insanların birbirleriyle olan fiziksel temasını azalttığını ve müşterilerin bu durumdan memnun olduğunu dile getirmiştir. 
Gastronomi 4.0 Üzerine Kavramsal Bir Araştırma

Emrah KESKIN, Nevres SEZEN

Barden ve arkadaşları (2012), telematik ziyafet uygulaması üzerine çalışmalar yapmıştır. Telematik ziyafet uygulaması, aynı ortamda bulunmayan müşterilerin iletişim teknolojisi aracılığıyla aynı atmosferi paylaşıyor hissi yaşayacağı bir hizmet sunmaktadır. Uygulamada ses ve görüntü aktarımı yapılmakta, bir tarafın el ve kol hareketinin karşı tarafın masa görüntüsüne etki ettiği ve aynı masadaymış hissiyatının oluştuğu bir ortam sunulmaktadır. Londra' da El Celler de Can Roca adlı restoranda yemek deneyimi sanal görüntüler eşliğinde yapılmaktadır. Yiyeceklerin vermek istediği tema, yemek deneyimi eşliğinde projeksiyon cihazları ile izlenmektedir. Deneyim esnasında görüntü, sanat, müzik, tat ve kokunun birleşmesinden dolayı burada gerçekleştirilen yemek deneyimine GastrOpera (gastronomi ve opera birleşimi) ismi verilmiştir (Spence ve Piqueras-Fiszman, 2013; Aksoy ve Akbulut, 2016). 4.0 uygulamalarının yemek masalarına yansıması, yemeklerin eğlenceli bir şekilde tüketilmesi müşteri memnuniyetinin artmasında önemli faktörlerdir. Gastronomi 4.0 gelişmeleri, yiyecek-içecek işletmelerinin maliyetine, türüne ve ortamına uygun olarak kullanıldığında gelir artışına da katkı sağlamaktadır (Kimes, 2008; Spence ve PiquerasFiszman, 2013). Bu nedenle gastronomi 4.0 gelişmelerinin yiyecek-içecek işletmelerinde doğru kullanımı işletme geleceği açısından faydalı olabilir.

\section{YÖNTEM}

Yiyecek-içecek sektöründe teknoloji kullanımında yaşanılan gelişmeleri belirlemeyi amaçlayan bu çalışmada nitel araştırma yöntemlerinden birisi olan doküman analizi tekniğinden faydalanılmıştır. Doküman analizi yazılı halde bulunan materyallerin incelendiği nitel araştırma desenlerinden birisi olarak tanımlanmaktadır (Yıldırım ve Şimşek, 2013).

\section{BULGULAR}

\subsection{Yiyecek-İçecek İşletmelerinde Görülen Teknolojik Gelişmelere Dair Örnekler}

Yiyecek-içecek işletmelerinde teknolojik gelişmelerden faydalanılarak misafirlere farklı deneyimler yaşatmak için belirli ürünler geliştirilmiştir. Bunlardan bazıları şu şekilde ifade edilebilir.

\section{- Garson Robotlar}

Kafe ve restoranlarda müşterilerin yoğunluğu, garson yetersizliği ve siparişlerin durumu ile ilgili karşılaşılan sorunları gidermek için "Waiter Robots" sistemi geliştirmiştir. "Waiter Robots" sistemi, müşteri siparişlerinin herhangi bir garson yardımı olmadan veya sipariş sıkışıklığı yaşanmadan LCD, tuş takımı ve bluetooth ile oluşturulan menü çubuğu aracılığıyla iletilmesi ve mutfakta hazırlanan yiyeceklerin garson robot aracılı̆̆ıyla müşteriye götürülmesi şeklinde tasarlanmıştır (Asif vd., 2015). 


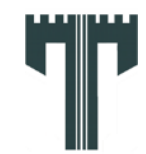

Gastroia: Journal of Gastronomy and Travel Research, Vol. 5, Issue 2,177-198 , 2021

Gastronomi 4.0 Üzerine Kavramsal Bir Araştırma

Emrah KESKIN, Nevres SEZEN

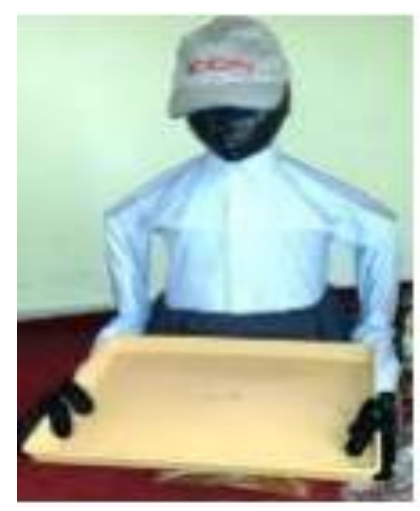

Resim 1

Kaynak: Asif vd. (2015)

\section{- E-menü}

E-menü, içeriğinde yemek listesi, yemeklerin içeriği, çeşitli oyunlar ve garsonsuz sipariş verme özelliğinin yanı sıra, yemeklerin mutfakta hazırlanma aşamasının izlenebildiği bir cihazdır (Margetis vd., 2013). Bu menüler vasıtası ile şubeye veya günlere özel ürün ya da fiyat tanımlanabilir. Menü tasarımları düzenlenebilir ve değiştirilebilir. Yiyeceklerin alerjen ve kalori bilgileri müşterilere yansıtılabilir ve müşteri isteklerine göre memnuniyet ölçülebilir (www.restapp.com.tr, 2019).

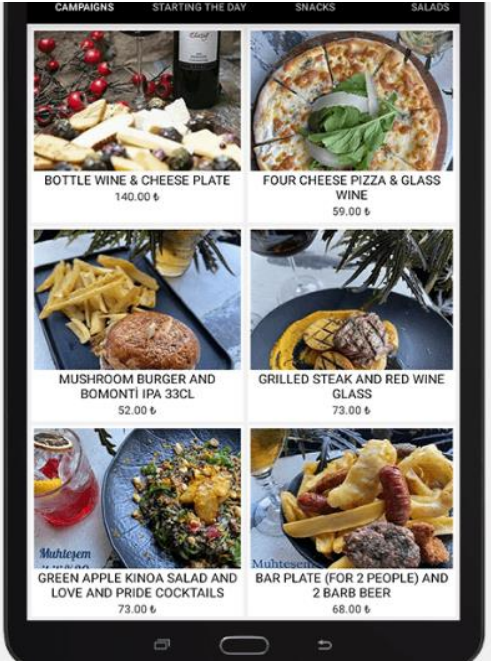

\section{Resim 2}

Kaynak: menulux.com, 2015 


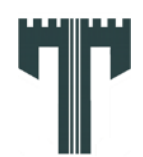

Gastroia: Journal of Gastronomy and Travel Research, Vol. 5, Issue 2,177-198 , 2021

Gastronomi 4.0 Üzerine Kavramsal Bir Araştırma

Emrah KESKIN, Nevres SEZEN

\section{- Robot Pepper}

Robot Pepper, Mastercard, Pizza Hut ve Softbank Robotics'in ortaklığı ile tasarlanmıştır. Pepper, Singapur'da Pizza Hut'ta menü önerileri vermekte ve sipariş alabilmektedir. Pepper'ın hizmetinden yararlanmak isteyen müşteriler telefonlarına Pizza Hut uygulamasını indirip, Masterpess ile oturum açarak dört haneli bir şifre aracılığıyla iletişime geçebilmektedir (Düşük, 2018; Mogg, 2018).

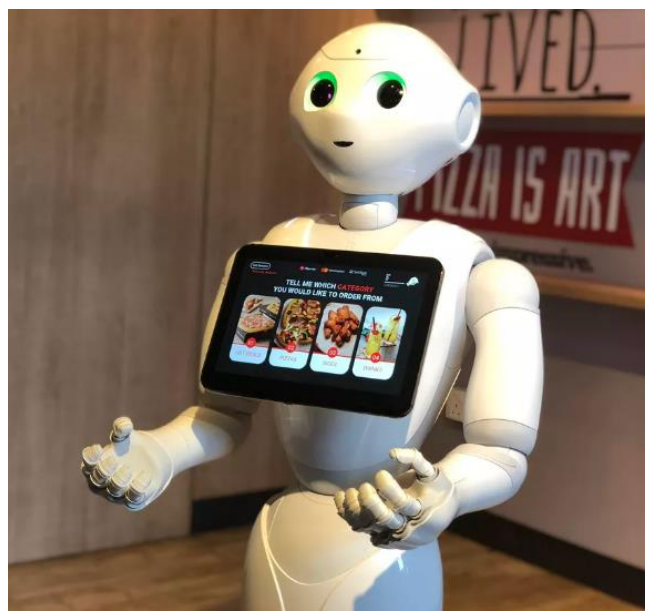

\section{$\operatorname{Resim} 3$}

Kaynak: www.cnet.com, 2018

\section{- Robotic Bar}

Dünyanın ilk robotik barmeni İtalyan robot şirketi Makr Shakr tarafından tasarlanmış ve ilk kez Royal Caribbean' da kullanılmaya başlanmıştır. "Shaken" ve "Stirred" isimli robotlar her çeşit içeceği karıştırma, sallama ve süzebilme özelliğine sahiptir. Müşteriler bardaki dijital ekrandan siparişlerini verebilmekte ve siparişler hazırlandığında SeaPass kartı veya WowBand'e dokunma işlemi ile robot barmenler tarafindan servis edilmektedir. Dakikada iki adet içecek hazırlayabilen "Shaken" ve "Stirred", günde yaklaşık bin adet içki yapabilme kapasitesine sahiptir (www.royalcarribean.com, 2016). 


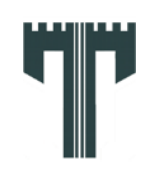

Gastroia: Journal of Gastronomy and Travel Research, Vol. 5, Issue 2,177-198 , 2021

Gastronomi 4.0 Üzerine Kavramsal Bir Araştırma

Emrah KESKIN, Nevres SEZEN

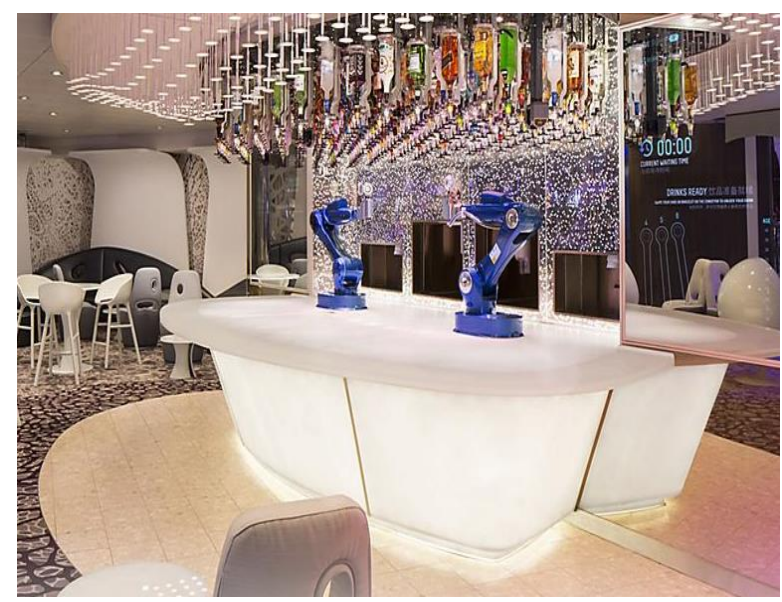

Resim 4

Kaynak: www.royalcaribbean.com, 2018

\section{- Koya ve Kona}

Japonya'da üretilen ve 2015 yılında Çin'in Şangay kentinde bir ramen restoranında çalışma hayatına başlayan Koya ve Kona, müşterilerine ramen (Uzakdoğu mutfağı yemeği) hazırlamaktadır. Koya ve Kayı, rameni kaynatma ve doğru miktarda servis etme gibi bilgilere hâkimdir. Ayrica tüm bu işlemi doksan saniyede yapabilmektedir (www.chinadaily.com, 2015).

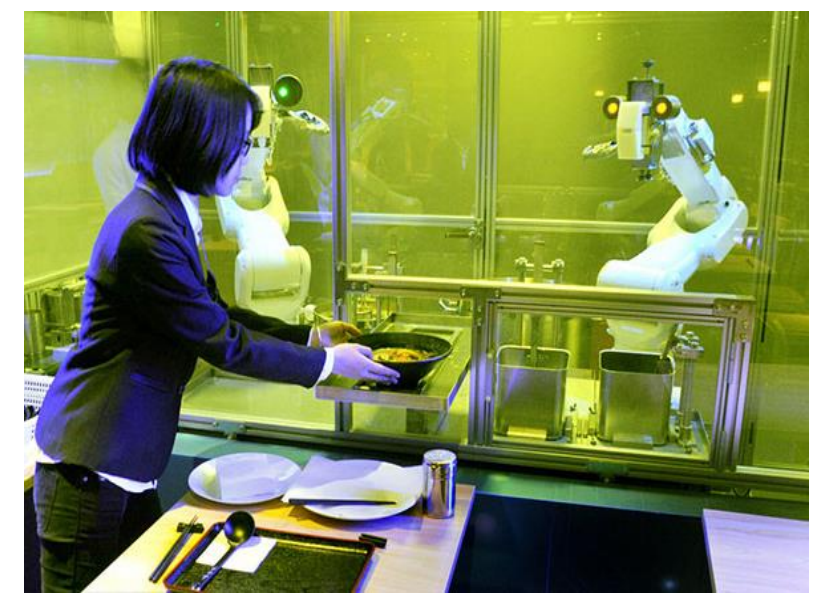

\section{Resim 5}

Kaynak: www.chinadaily.com, 2015 


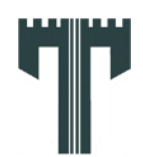

Gastroia: Journal of Gastronomy and Travel Research, Vol. 5, Issue 2,177-198 , 2021

Gastronomi 4.0 Üzerine Kavramsal Bir Araştırma

Emrah KESKIN, Nevres SEZEN

\section{- Moley}

Dünyanın ilk robot şefi olan Moley, 18 yıllık bir çalışma sonucunda 2015 yılında tasarlanmıştır. Mutfakta insan eline yakın derecede davranışlar sergileyen Moley'i kullanmak için akıllı telefon veya mutfağa yerleştirilen dokunmatik ekran gereklidir. Bu sayede müşteriler istenilen yemeği seçtikten sonra yemeğin hazırlanışını cam bölmenin ardında izleyebilmektedir (Erkılıç, 2016).

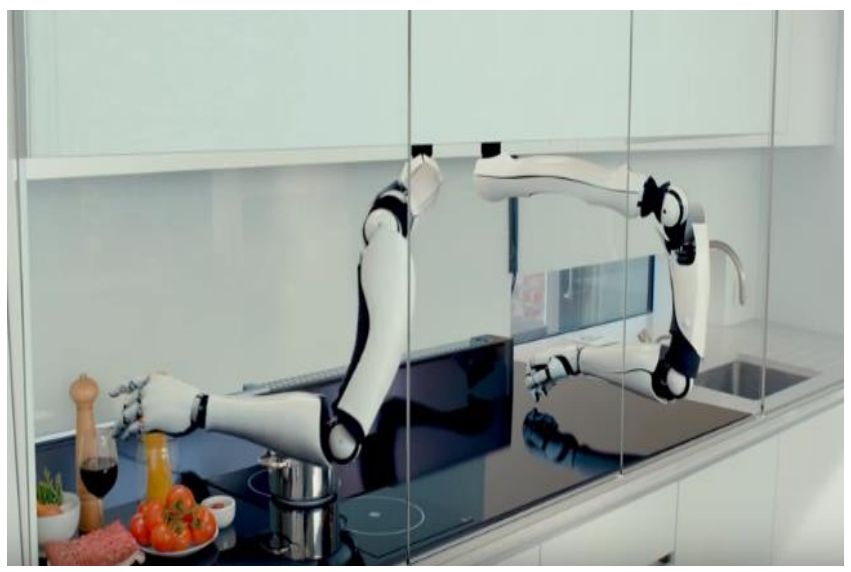

\section{Resim 6}

Kaynak: Erkılıç, 2016.

\section{- Flippy}

Fastfood restoranlarında patates ve soğan halkası gibi on dokuz çeşit ürün hazırlayabilen Flippy, yiyecekleri bir ray üzerinde hareket ederek hazırlamaktadır. Özellikle Covid-19 salgını döneminde insanlar ve yiyecekler arasındaki fiziksel temasın en aza indirilmesine bir örnektir. Flippy gibi robotlar aracılığıyla yiyecekler ile yakın temasın önlendiği restoranlar salgın dönemleri ve insanların fiziksel temastan kaçınmak istediği dönemler için diğer restoran türlerine göre rekabet avantajı sağlamaktadır (Meisenzahl, 2020). 


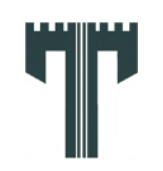

Gastroia: Journal of Gastronomy and Travel Research, Vol. 5, Issue 2,177-198 , 2021

Gastronomi 4.0 Üzerine Kavramsal Bir Araştırma

Emrah KESKIN, Nevres SEZEN

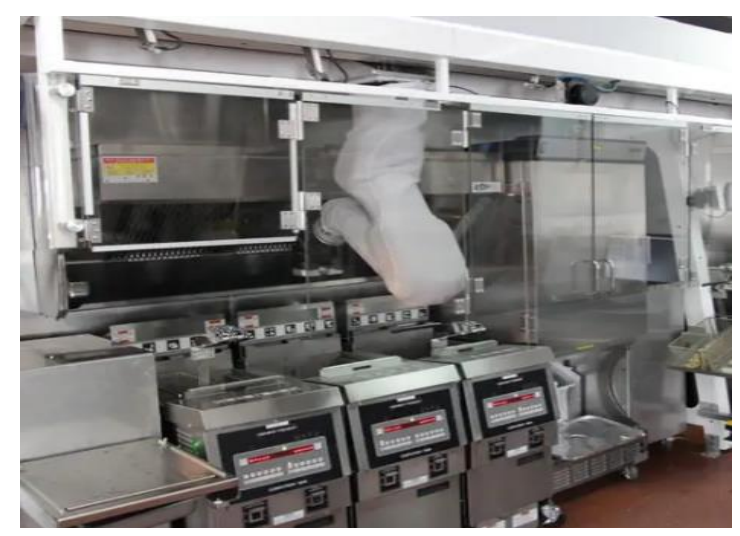

Resim 8

Kaynak: Meisenzahl, 2020.

\section{- BellaBot}

Çin'de tasarlanan BellaBot, ev ve restoranlarda yemek dağıtım için kullanılan bir robottur. Üstün insan-robot etkileşimi olan BellaBot yenilikçi bir tasarıma sahiptir. Herhangi bir açıda durabilir ve hareket ederken on metrelik bir alan içinde karşısına bir engel çıktığında uzaklaşabilir. Siparişlerin müşteriye iletilmesinde üzerindeki dokunmatik ekrandan istenilen yer veya açı ayarlanabilen bu robot mutlu, şaşkın, üzgün ve sevimli gibi on dört çeşit yüz ifadesi sayesinde müşterilerin ruh haline göre davranış sergileyebilmektedir (www.wallexbot.com, 2020).

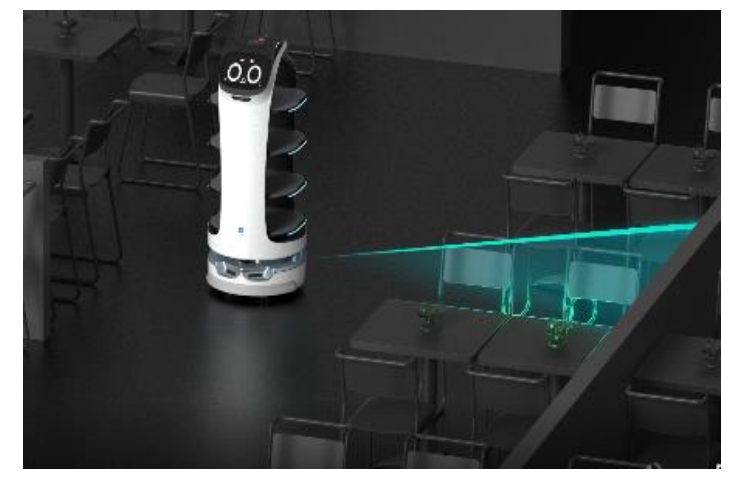

\section{Resim 9}

Kaynak: www.wallexbot.com, 2020.

\section{- HolaBot}

Çin'de tasarlanan HolaBot, ilk tabak toplama robotudur. HolaBot, jest ve sesleri algilayan, 6 katlı ve 120 kilograma kadar taşıma kapasitesi olan, dokunma işlemine gerek kalmadan 


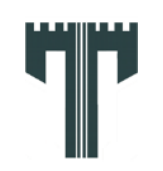

Gastroia: Journal of Gastronomy and Travel Research, Vol. 5, Issue 2,177-198 , 2021

Gastronomi 4.0 Üzerine Kavramsal Bir Araştırma

Emrah KESKIN, Nevres SEZEN

tablet, akıllı saat ve çağrı cihazı gibi ürünler ile görev talimatı verilebilen ve işletmenin verimliliğini arttırmada yararlı olan bir robottur (www.wallexbot.com, 2020).

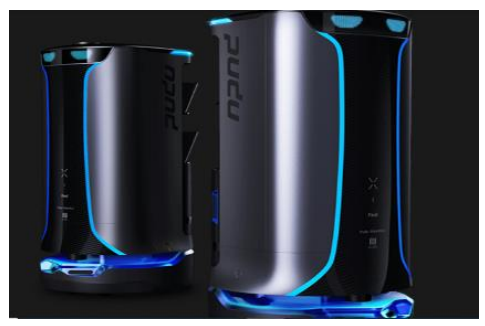

\section{Resim 10}

Kaynak: www.wallexbot.com, 2020

Mutfak robotları, iş gücünde zamandan ve insan enerjisinden tasarruf sağlamanın yanı sıra, el ile olan teması en aza indirecek düzeyde yiyecek üretimine olanak sağladığı için yiyeceklerin sağlıklı ortamda ve hızlı hazırlanmasında etkili olmaktadır. Ayrıca bu robotlar insanlardan gelen birçok komutu anlamakta ve tepki verebilmektedir. Robotların bazıları müşteriler ile iletişim esnasında, müşterinin yönelttiği bir soruya fiziki yanıt vermesinin yanında, müşterilere duygu aktarımı sağlamak için insanlara ait çeşitli yüz ifadelerini taklit edebilmektedir. Robotların bu özellikleri müşteriler açısından dikkat çekici ve keyifli bir deneyim olmaktadır. Bu nedenle robotların işletmeye faydaları oldukça fazladır. Dolayısıyla 4.0 uygulamaları sayesinde üretilmiş olan bu mutfak robotları, insan hayatını kolaylaştırmak, işletmeleri çekici kılmak, işletme kârlılığı sağlamak ve sağlıklı ürünler hazırlamak için kullanılan cihazlardır.

\section{SONUÇ VE ÖNERILER}

Dünya, günümüz teknolojik çağında yaşanan gelişmelerden birçok açıdan etkilenmektedir. Teknolojik alanda yaşanan gelişmelerden etkilenen ve endüstriyel açıdan yükseliş yaşayan sektörlerden biri de turizm sektörüdür. Teknolojik alanda gerçekleştirilen birçok yenilik turizm sektöründe deneyimlenmektedir. Akıllı cihazlar, post cihazları, e-menüler, uzaktan rezervasyon, arttırılmış gerçeklik uygulamaları ve sanal turlar turizm sektöründe görülen teknoloji kullanımlarıdır (Mutlu Öztürk, 2020).

Turizmde müşteri ile ilişkilerde memnuniyet meydana getiren akıllı cihazlar, bazı kitleler tarafindan kabul görmemektedir (Mil ve Dirican, 2018). ABD, Çin ve New York gibi ileri teknolojiye sahip ülke ve eyaletlerde teknolojiyi işletmesinde tamamıyla kullanan bazı işletmeler, akıllı cihazları pozitif yönde değerlendirerek müşterilere robotiklerin hizmet verdiği bir ortam sağlamaktadır (Özgüneş vd., 2020). 


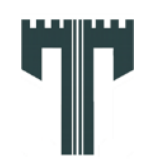

Gastroia: Journal of Gastronomy and Travel Research, Vol. 5, Issue 2,177-198 , 2021

Gastronomi 4.0 Üzerine Kavramsal Bir Araştırma

Emrah KESKIN, Nevres SEZEN

Turizmde önemli bir yere sahip olan yiyecek-içecek sektöründe de Endüstri 4.0 etkileri görülmüş ve bu durum Gastronomi 4.0 olarak adlandırılmıştır. Gastronomi 4.0; yiyecekiçecek sektöründe insan teması ile yapılması gerekli olan yemek, servis, sipariş, dağıtım ve toplama gibi insanın sanatsal, zihinsel ve fiziksel enerjisini gerektiren birçok işin yenilikçi tasarımla oluşturulan farklı isim ve görevlerdeki cihaz ve robotlar ile yapılmasına verilen isimdir (Mutlu Öztürk, 2020).

Yiyecek-içecek sektöründe insan teması olmadan verilen hizmetin, müşteriyi memnun etmeyeceği yönünde düşünceler mevcuttur. Fakat teknolojik çağda insanların çağın sunduğu hizmetlere yönelik beklentileri oldukça fazladır. Robotik cihazların kullanıldığı restoran, kafe ve diğer işletmelere gösterilen rağbet teknolojinin yiyecek-içecek sektöründe bazı kitlelerce kabul edildiğini göstermektedir (Spence ve Piqueras-Fiszman, 2013).

Özellikle salgın dönemlerinde insanların birbiri ile olan yakın temasın vereceği zararlar düşünüldüğünde robotlar yardımıyla yapılan ve servis edilen yiyeceklerin daha fazla tercih edilebileceği düşünülmektedir. Robotların kullanıldığı mutfaklarda yapılan yiyeceklerde insan eli lezzetinin olamayacağını düşünen bir kitle de mevcuttur. Fakat tasarlanan robotlar ayarlanan otomasyon sistemine göre istenilen yiyeceğin içerisinde hangi ürünlerin olduğu, yemeklere hangi ürünlerin ne kadar miktarda koyulması gerektiği ve servis tabağına ne kadar miktar koyulacağı gibi konularda bilgi sahibidir (Alexis, 2017; Ivanov vd., 2017).

Yiyecek-içecek sektörü ve turizm içerisinde yer edinmiş birçok işletme tasarlanan robot ve diğer akıllı cihazlardan verimlilik sağlamak istemektedir. Bu nedenle Endüstri 4.0 teknolojilerin turizm ve gastronomi sektöründe de artacağ düşünülmektedir (Güneş vd., 2018).

Turizm 4.0 ve Gastronomi 4.0 gelişmelerinin birçok kitle tarafında kabul görmesi için insanların robot kullanımına yönelik bakış açılarının pozitif yönde gelişmesi gerekmektedir. Yiyecek-içecek sektörüne yönelik düzenlenen konferans ve söyleşilerde robot ve diğer akı1lı cihazların tanıtımı ve işletmelere sağladığı faydalar hakkında bilgi aktarılması teknoloji kullanımının artmasına katkı sağlayabilir. Küresel olarak insanların reklamları takip ettiği televizyon ve internet ortamlarında, robot ve diğer akıllı cihazların insanların iş hayatına olan katkıları teknolojiye yönelik bakış açısını olumlu yönde etkileyebilir. Mutfak ortamında kullanılan robotlara verilen talimatların arka planına mutfak çalışanlarının görevlendirilebileceği bir ortam oluşturularak mutfak çalışanlarının işsiz kalma korkusuna yönelik düşüncelerin önüne geçilebilir.

Mutfak robotlarının hazırladığı yemeklerin insanların hazırladığı yemekler kadar dikkatli ve özenli olduğunu yalnızca teknolojik deneyimleri seven insanların değil, aynı zamanda geleneksel yemeklerin geleneksel yöntemlerle yapılmasından hoşlanan insanların da deneyimlemesi robotlara yönelik ön yargıları azaltabilir. Ayrıca robotların güvenilirliğini 
Gastronomi 4.0 Üzerine Kavramsal Bir Araştırma

Emrah KESKIN, Nevres SEZEN

kanıtlamak ve gelecekte insanların yaşamlarına ve iş hayatlarına zarar vermeden hayatımızda yer alabileceğini göstermek için, tasarlanan robotların yemek şirketlerine, okullara, otellere, iş yeri yemekhanelerine satışının arttırılmasına yönelik faaliyetler yapılabilir. Böylelikle teknolojik gelişmeler yeme-içme sektöründe de gelişme gösterebilir.

\section{KAYNAKÇA}

Aksoy, M. \& Akbulut, B.A. (2016, Mayıs). Restoranlardaki teknolojik yeniliklerin deneyim pazarlaması açısından değerlendirilmesi. II. Eurasia International Tourism Congress: Current Issues, Trends, and Indicators, Konya.

Alexis, P. (2017). R-Tourism: Introducing the potential impact of robotics and service automation in tourism. Ovidius University Annals, Series Economic Sciences, 17(1), 211-216.

Asif, M. Sabeel, M. Rahman, M. \& Khan, Z. H. (2015). Waiter robot - solution to restaurant automation. Proceedings of the 1st Student Multi Disciplinary Research Conference (MDSRC), Wah.

Augment, (2016). The Evolution of eCommerce Over the Last Decade [online]. Augment News. Erişim: https://www.augment.com/. Erişim tarihi: 15.03.2021.

Avcı, B. (2020). Artırılmış gerçeklik teknolojisi turizm için neden önemli? Turizm günlüğü turizm ve seyahat gazetesi. https://www.turizmgunlugu.com/2020/02/01/artirilmisgerceklik-teknolojisi-turizm/. Erişim tarihi: 16.01.2021.

Aydın, B. (2016). Sosyal Medyada Restoran İmaj1: Tripadvisor Örneği . Journal of Multidisciplinary Academic Tourism , 1 (1) , 13-30 . DOI: 10.31822/jomat.287998

Barden, P. Comber, R. Green, D. Jackson, D. Ladha, C. Bartindale, T. Bryan-Kinns, N. Stockman, T. \& Olivier, P. (2012). Telematic dinner party: Designing for togetherness through play and performance. Proceedings of the ACM Conference on Designing Interactive Systems 2012 (DIS2012). New York, NY: ACM.

Bec, A. Moyle, B. Timms, K. Schafer, V. Skavronskaya, L. \& Little, C. (2019). Management of immersive heritage tourism experiencs: a conceptual model. Tourism Management, 72, 117-120.

Bodkhe, U. Tanwar, S. Parekh, K. Khanpara, P. Tyagi, S. Kumar, N. \& Alazab, M. (2020). Blockchain for industry 4.0: A comprehensive review. IEEE Access 8, 79764-79800. 
Gastronomi 4.0 Üzerine Kavramsal Bir Araştırma

Emrah KESKIN, Nevres SEZEN

Case, A. (2015). Calm technology: principles and patterns for non-intrusive design. O'Reilly Media Inc, Sebastopol. https://www.oreilly.com/library/view/calmtechnology/9781491925874/index.html. Erişim tarihi: 18.01.2021.

Chandler, S. (2020). Virtual reality concert in Helsinki attracts over 1 million spectators. 8 mayis, 2020, https://cacm.acm.org/news/244773-vr-concert-in-helsinki-attractsover-1-million-spectators/fulltext . Erişim tarihi: 12.01.2021.

Cheung, C. W. Tsang I.T. \& Wong, K.H. (2017). Robot Avatar: A virtual tourism robot for people with disabilities. International Journal of Computer Theory And Engineering, 9(3), 229- 234.

Cohen, S. \& Hopkins, D. (2019). Autonomous vehicles and the future of urban tourism. Annals of Tourism Research, 74, 33-42.

Diez-Olivan, A. Ser, J-D. Galar, D. \& Sierra, B. (2019). Data fusion and machine learning for industrial prognostic: Trends and perspectives toward Industry 4.0. Information Fusion, 50, 92-111.

Dinçer, F.I. Bayram, G.E. \& Altunöz, O. (2020). Fourth generation of rights and their refections on human resources practices in tourism businesses. (Aydın Ş, Dedeoglu, B.B. \&Çoban, Ö.) Organizational behavior challenges in the tourism industry. IGI Global, Hershey, ss 60-81.

Düşük, A. (2018). Pizza Hut, Singapur'da Pepper robot siparişi verdi. https://www.cnet.com/news/pizza-hut-trials-robot-ordering-service-in-singapore/.

Erişim tarihi: 21.21.2021.

Erkılıç, G. (2016) Dünyanın ilk robot şefi Moley. https://bigumigu.com/haber/mutfaktakiyeni-yardimciniz-moley/. Erişim tarihi: 26.01.2021.

Eröz, S. S. \& Doğdubay, M. (2012). Turistik ürün tercihinde sosyal medyanın rolü ve etik ilişkisi. Dokuz Eylül Üniversitesi İktisadi İdari Bilimler Fakültesi Dergisi, 27(1), 133-157.

Fes, N. (2018). Blockhain in tourism: Hope or hype. Tourism Review (online), 18.06.2018. Erişim adresi: https://www.tourism-review.com/blockchain-in-tourism-worldnews10635. Erişim tarihi: 15.03.2021.

García-Segoviaa, P. Garridob, M. D. Vercetc, A. Arboleyad, J. C. S.Fiszmane, MartínezMonzoa, J. \& Ruiz, J. (2014). Molecular gastronomy in spain. Journal of Culinary Science \& Technology, 4 (12), 279-293. 


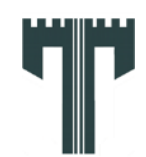

Gastroia: Journal of Gastronomy and Travel Research, Vol. 5, Issue 2,177-198 , 2021

Gastronomi 4.0 Üzerine Kavramsal Bir Araştırma

Emrah KESKIN, Nevres SEZEN

Gretzel, U. Werthner, H. Koo, C. \& Lamsfus, C. (2015). Conceptual foundations for understanding smart tourism ecosystems. Computer in Human Behavior 50, 558 563.

Güneş, E. Biçer, Ş. Özkan, M. \& Nizamlıŏlu, H. F. (2018). Gastronomy four zero. International Journal of Environmental Pollution \& Environmental Modelling, 1(3), 77- 84.

Hausold, A. (2017). Unlock the ultimate travel experience with cryptocurrency incentives, TourismReview, 23 Oct 2017. https://www.tourism-review.com/trippki-introducedbrand-new-travel-reward-system-news10343. Erişim tarihi: 18.01.2021.

Hall, M. \& Sharples, L. (2003). The consumption of experiences or the experience of consumption? An introduction to the tourism of taste in Food Tourism Around the World Development, management and markets, (Hall, M.C. Sharples, L. Michell, R. Macionis, N. \& Cambourne, B.) (I. Series), Butterworth-Heinemann an Imprint of Elsevier Linacre, Burlington.

Ivanov, S. H. Webster, C. \& Berezina, K. (2017, 18-19 May). Adoption of robots and service automation by tourism and hospitality companies, Invtur Conference, Aveiro, Portugal.

Ivanov, S. (2020). The impact of automation on tourism and hospitality jobs. Information Technology \& Tourism, 22(2),205-215.

Jang, H. W. \& Lee, S. B. (2020). Serving Robots: Management and applications for restaurant business sustainability. Sustainability, 12(0), 1-15.

Karakuş, Y. (2020). Otel işletmelerinde mobil teknolojilerin kullanımı. T. Pala \& M. Tepeci (Ed.), Otel İsletmelerinin Yönetimi - Operasyonel Süreç ve Yönetim Uygulamaları içinde (ss. 205-222). Ankara: Detay Yayıncılık.

Karakuş, Y. Onat, G. \& Özdemir, G. (2020). Yerel Halkın Gastronomi Turizmi Çağrışımları ve Beklentileri: Göreme Kasabası Örneği . Journal of Tourism and Gastronomy Studies, 2020(3), 2179-2201. doi:10.21325/jotags.2020.655

Kim, M. \& Qu, H. (2014). Travelers' behavioral intention toward hotel self-service kiosks usage. International Journal of Contemporary Hospitality Management, 26(2), 225245.

Kimes, S. E. (2008). The roles of technology in restaurant revenue management. Cornell Hospitality Quarterly, 49(3), 297-309. 


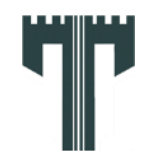

Gastroia: Journal of Gastronomy and Travel Research, Vol. 5, Issue 2,177-198 , 2021

Gastronomi 4.0 Üzerine Kavramsal Bir Araştırma

Emrah KESKIN, Nevres SEZEN

Korže, S.Z. (2019). From industry 4.0 to tourism 4.0. Innovative Issues and Approaches in Social Sciences, 12, 29-52.

Lehaney, B. Clarke, S. Kimberlee, V. Spencer-Matthews, S. Lehaney, B. Clarke, S. \& Spencer-Matthews, S. (1999). The human side of information systems development: A case of an intervention at a British visitor attraction. J Organ End User Comput (JOEUC) 11(4), 33-39.

Lessiter, J. Mitchell, S. Ferrari, E. Borden, P. Bakhshi, H. \& Freeman, J. (2018). Evaluating immersive user experience and audience impact report authors. https://www.immerseuk.org/wpcontent/uploads/2018/07/Evaluating_Immersive_User_Experience_and_Audience Impact.pdf.

Linden, E. McClements, D. J. \& Ubbink, J. (2008). Molecular gastronomy: A food fad or an Iterface for science-based cooking? Food Biophysics 3, 246-254.

Margetis, G. Grammenos, D. Zabulis, X. \& Stephanidis, C. (2013). iEat: An interactive table for restaurant customers' experience enhancement. In International Conference on Human-Computer Interaction Springer, Berlin, Heidelberg.

Meisenzahl, M. (2020). Flippy, the $\$ 30,000$ automated robot fast-food cook, is now for sale with 'demand through the roof' - see how it grills burgers and fries onion rings. https://www.businessinsider.com/miso-robotics-flippy-robot-on-sale-for-3000002020-10. Erişim tarihi: 20.01.2021.

Mil, B. \& Dirican, C. (2018). Endüstri 4.0 teknolojileri ve turizme etkileri. Disiplinlerarası Akademik Turizm Dergisi, 3(1), 1-9.

Mogg, T. (2018). Pepper's next gig is at Pizza Hut, but the robot won't be tossing any dough. https://www.digitaltrends.com/cool-tech/pepper-working-at-pizza-hut/ . Erișim tarihi: 21.01.2021.

Murphy, J. Gretzel, U. \& Pesonen, J. (2019). Marketing robot services in hospitality and tourism: the role of anthropomorphism. Journal of Travel Tourism Marketing, 36(7),784-795.

Mutlu Öztürk, H. (2020). Teknolojik gelişmeler ve teknoloji alanına yansımaları: Gastronomi 4.0. Güncel Turizm Araştırmaları Dergisi, 4(2), 222-239. 


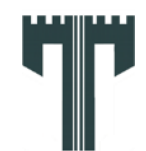

Gastroia: Journal of Gastronomy and Travel Research, Vol. 5, Issue 2,177-198 , 2021

Gastronomi 4.0 Üzerine Kavramsal Bir Araştırma

Emrah KESKİN, Nevres SEZEN

Neuhofer, B. Buhalis, D. \& Ladkin, A. (2014). A typology of technology-enhanced tourism experiences. International Journal of Tourism Research, 16(4), 340-350.

Noodle chef robots prove popular in Shanghai. https://www.chinadaily.com.cn/trending/2015-12/25/content_22805115.htm. Erişim tarihi: 22.01.2021.

Özgüneş, R. E. Bozok, D. \& Küçükaltan, D. (2020). Yiyecek ve içecek sektöründe ileri teknoloji ve pandemik düzene doğru: Yakın gelecekte bir robota 'eline sağlik!' diyebilir miyiz? Afyon Kocatepe Üniversitesi Sosyal Bilimler Dergisi, 22(4), 11241139.

Papathanassis, A. (2017). R-Tourism: Introducing the potential impact of the robotics and service automation in tourism. Ovidius University Annais, Economic Science Series, 17(1), 211-216.

Park, S.C. (2017). The fourth industrial revolution and implications for innovative cluster policies, AI\&Society, 33, 433- 445.

Peceny, U.S. Urbanicic, J. Mokorel, S. Kuralt, V. \& Ilijaš, T. (2019). Tourism 4.0: Challenges in marceting a paradigm shift. Consumer Bahaviour and Marketing, IntechOpen.

Pencarelli T. (2019). The digital revolution in the travel and tourism industry. Information Technology \& Toursim, 22, 455-476.

Peraković, D. Periša, M. \& Cvitić, I. (2018). Analysis of the possible application of assistive technology in the concept of industry 4.0. In: Proceedings the Thirty-Sixth Symposium on Novel Technologies in Postal and Telecommunication TrafficPosTel 2018, pp. 175-184. Pekograf d.o.o. Belgrade, Republic of Serbia (2018).

Peraković, D. Periša, M. \& Zorić, P. (2019). Challenges and Issues of ICT in Industry 4.0. advances in design. Simulation and Manufacturing II, 259-269.

Porter, M. E. \& Heppelmann, J. E. (2014). How smart, connected products are transforming competition. Harvard Business Review, 92(11), 64- 88.

Robot bartenders shake things up at sea. https://www.royalcaribbean.com/blog/robotbartenders-shake-things-up-at-sea/. Erişim tarihi: 22.01.2021.

Rodič, B. (2017). Industry 4.0 and the new simulation modelling paradigm, Organizacija, 50 (3), 193-207.

Schwab, K. (2016). The fourth industrial revolution, Penguin Rendom House. 


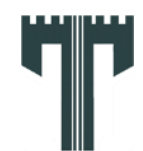

Gastroia: Journal of Gastronomy and Travel Research, Vol. 5, Issue 2,177-198 , 2021

Gastronomi 4.0 Üzerine Kavramsal Bir Araştırma

Emrah KESKİN, Nevres SEZEN

Seyitoğlu, F. \& Ivanov, S. (2020). Service robots as a tool for physical distancing in tourism. Current Issues in Tourism, 1-4.

Slivar, I. Stankov, U. \& Pavluković, V. (2019). Case study: delegated distribution: hotels should be warned! An example from Croatia. Transnational Marketing Journal $7(2), 245-256$.

Spence, C. \& Piqueras-Fiszman, B. (2013). Technology at the dining table. Flavour, 2(1), 16.

Stankov, U. \& Filimonau, V. (2019a). Co-creating "Mindful" holiday resort Experience for guests' digital Well-Being. In J. Pesonen \& J. Neidhardt (Eds.), Information and communication technologies in tourism 2019 (pp. 200-211). Springer International Publishing.

Stankov, U. \& Gretzel, U. (2020). Tourism 4.0 technologies and tourist experiences: a human-centered design perspective. Information Technology \& Tourism. 22, 477488.

Şahin, N.N. \& Doğdubay, M. (2017). Endüstri 4.0'ın yiyecek ve içecek sektöründe kullanılabilirliği(swot/gzft analizi ile bir değerlendirme). (D. Bozok, C. Avcıkurt, M. Doğdubay, M. Sarıŏlan ve G. K. Girgin). Gastronomi Üzerine Araştırmalar, Ankara, Detay Yayıncılık.

Verevka, T. (2018). Verevka, T. Key performance indicators of high-tech enterprises. SHS Web of Conferences 44, 00077.

Yıldırım, A. \& Şimşek, H. (2013). Sosyal bilimlerde nitel araştırma yöntemleri. Ankara. Seçkin Yayınları.

Yu, C. E. (2020). Humanlike robots as employees in the hotel industry: Thematic content analysis of online reviews. Journal of Hospitality Marketing \& Management, 29(1), 22-38.

Zhang, X. Yang, S. Srivastava, G. Chen, M. Y. \& Cheng, X. (2020). Hybridization of cognitive computing for food services. Applied Soft Computing, 89, 1-8.

www.menulux.com. https://www.menulux.com/restoran-otomasyonu/dijital-menu/tabletmenu-programi. Erişim tarihi: 22.01.2021.

www.royalcaribbean.com. 
Gastroia: Journal of Gastronomy and Travel Research, Vol. 5, Issue 2,177-198 , 2021

Gastronomi 4.0 Üzerine Kavramsal Bir Araştırma

Emrah KESKIN, Nevres SEZEN

https://blog.royalcaribbean.com.tr/gemiler/kokteyllerinizi-bionicbar-robot-barmenlerhazirlayacak. Erişim tarihi: 19/02.2021

https://www.royalcaribbean.com/cruise-dining/bionic-bar. Erişim tarihi: 22.01.2021. www.wallexbot.com. https://www.wallexbot.com/pages/bellabot.html, Erişim tarihi: 28. 01. 2021

www.restapp.com.tr. https://www.restapp.com.tr/ Erişim tarihi: 22.01.2021. 